\title{
Doctor-Patient Trust Among Chronic Pain Patients on Chronic Opioid Therapy after Opioid Risk Reduction Initiatives: A Survey
}

\author{
Karen J. Sherman, PhD, Rod L. Walker, MS, Kathleen Saunders, JD, \\ Susan M. Shortreed, PhD, Michael Parchman, MD, MPH, \\ Ryan N. Hansen, PharmD, PhD, Manu Thakral, PhD, NP, Evette J. Ludman, PhD, \\ Sascha Dublin, MD, PhD, and Michael Von Korff, ScD
}

Objective: This analysis examined patients' perceptions about trust within the doctor-patient relationship related to managing opioid pain medications. We compared perceptions among chronic opioid therapy (COT) patients who were and were not exposed to opioid risk reduction initiatives.

Methods: Between 2014 and 2016, we surveyed 1588 adults with chronic pain receiving COT about their trust in their prescribing doctor, their perceptions of their doctor's trust in them, their concerns about opioid prescribing, and their knowledge of opioid safety concerns. The population included adults receiving care in intervention settings that implemented opioid risk reduction initiatives and control settings with similar COT patients that did not.

Results: Overall, 82.2\% of COT patients said they trusted their doctor's judgment, with more agreement among patients in the control clinics $(86.3 \% ; n=653)$ than in the intervention clinics $(77.9 \%$; $\mathrm{n}=935 ; \boldsymbol{P}=.002)$. Similarly, slightly more patients in the control clinics believed their physician trusted how they managed their opioid pain medicines $(91.1 \%)$ compared with the intervention clinics $(86.2 \% ; P=.002)$. The percent who worried that their doctor would stop prescribing opioid pain medicine was $29.3 \%$ in intervention clinics and $21.8 \%$ in control clinics $(P=.007)$.

Conclusions: Although COT patients typically reported favorable perceptions of doctor-patient trust in managing opioid pain medicines, implementation of opioid risk reduction initiatives may have reduced levels of trust for a minority of COT patients. This suggests that it may be possible to implement opioid risk-reduction initiatives while sustaining high levels of doctor-patient trust for most COT patients. (J Am Board Fam Med 2018;31:578-587.)

Keywords: Chronic Pain, Opioid Analgesics, Pain Management, Physician-Patient Relations, Risk Reduction Behavior

A good doctor-patient relationship is an important goal of patient-centered care and is associated with better outcomes for many medical conditions. ${ }^{1,2}$ Mutual trust is a critical ingredient in this relation-

This article was externally peer reviewed.

Submitted 19 January 2018; revised 2 April 2018; accepted 3 April 2018.

From Kaiser Permanente Washington Health Research Institute, Seattle, WA (KJS, RLW, KS, SMS, MP, RNH, MT, EJL, SD, MVK); Department of Epidemiology, University of Washington, Seattle (KJS, SD); Department of Biostatistics, University of Washington, Seattle (SMS); Department of Psychosocial and Community Health, School of Nursing, University of Washington, Seattle (MT); Departments of Pharmacy and Health Services, University of Washington, Seattle (RNH). ship. ${ }^{3,4}$ Yet, for patients with chronic pain, where the underlying cause is often unknown and definitive treatments are lacking, this relationship is often

Funding: This study was funded by an award to Group Health Research Institute (now Kaiser Permanente Washington Health Research Institute) from the Patient-Centered Outcomes Research Institute (IHS-1306-02198, Michael Von Korff, principal investigator). Dr. Thakral was supported by a grant from the National Institute on Aging, T32-AG02767709. The conclusions in this report are solely the responsibility of the authors and do not necessarily represent the views of the Patient-Centered Outcomes Research Institute (PCORI), its Board of Governors or Methodology Committee.

Conflict of interest: Ms. Saunders owns stock in Merck. The remaining authors report no conflicts. 
challenging. ${ }^{5,6}$ Patients frequently feel dismissed, struggle to have their pain acknowledged, and are consequently frustrated with their care. ${ }^{7-9}$ Among patients receiving chronic opioid therapy (COT), the doctor-patient relationship can seem adversarial; some patients feel that their physicians believe they are "drug seeking," ${ }^{10}$ and some physicians have experience with patients who deceived them to obtain opioid prescriptions for nonmedical use. ${ }^{10-12}$ As risks of COT are becoming better understood, risk reduction guidelines have been proposed by a number of states ${ }^{13-15}$ and, more recently, by the Centers for Disease Control and Prevention. ${ }^{16}$ Such risk reduction guidelines often include having a single clinician manage all opioids, developing a COT care plan, checking prescription drug monitoring databases, educating patients about opioid risks, close monitoring including periodic urine drug testing, avoiding dose escalation, and tapering patients on high opioid doses to lower levels. Early reports indicate that such strategies can be successful, with Washington State demonstrating a $29 \%$ decrease in the rate of deaths attributed to overdoses of prescription opioids in the 5 years since the state implemented efforts to encourage the use of lower doses of opioids. ${ }^{17}$

Because risk reduction initiatives may call for reductions in opioid dose for COT patients, they might have adverse effects on already challenging doctor-patient relationships. Risk reduction initiatives also call for closer monitoring of COT patients, including more consistent use of urine drug screening, which may also raise questions for some COT patients. There is little information on how these initiatives impact the level of trust in the patient-doctor relationship among COT users. As part of a larger study designed to compare outcomes of a structured risk reduction initiative in a large integrated group practice to routine primary

Disclaimer: In the past 3 years, Dr. Von Korff was the principal investigator of grants to Group Health Research Institute from Pfizer Inc. that focused on opioids. These grants also supported work on opioids by Dr. Shortreed, Ms. Saunders, and Mr. Walker. Drs. Shortreed and Von Korff have also received funding from research grants awarded to KPWHRI by Syneos Health for FDA-mandated post-marketing surveillance studies of extended release opioids.

Corresponding author: Karen J. Sherman, PhD, 1730 Minor Ave., Ste. 1600, Seattle, WA 98122 (E-mail: sherman. k@ghc.org).

Prior Presentations: A version of this material was presented at the Health Care Systems Research Network Annual Meeting on April 11, 2018 in Minneapolis, MN. care in Washington State, we surveyed 2 random samples of COT patients: 1 from intervention settings that implemented opioid dose reduction and closer monitoring of COT patients, and 1 from control settings that did not implement these initiatives. In both settings, doctors had had longterm exposure to the Washington State risk reduction guidelines, which lacked state support to assist clinics with implementation. We hypothesized that doctor-patient trust would be lower in the intervention clinics where the opioid risk reduction initiatives were implemented compared with those control clinics that did not systematically implement such initiatives.

\section{Methods}

The survey data included in this report were collected as part of a larger study of patients using COT that was designed to document the effects of opioid dose and risk reduction initiatives on opioid outcomes and safety. ${ }^{18}$ The study was conducted at Group Health Cooperative, a consumer-governed, nonprofit integrated health care system in Washington State. ${ }^{19}$ In February 2017, Kaiser Permanente acquired Group Health Cooperative and it became known as Kaiser Permanente Washington. During the study period, roughly two-thirds of members (about 400,000 persons) received their comprehensive care from Group Health clinicians at Group Health-owned clinics and these patients were exposed to the intervention. In the intervention clinics, most prescribers were family medicine physicians, about half of whom were female. ${ }^{18,20}$ COT patients were less than $3 \%$ of their adult patients. ${ }^{18,20}$ The remaining members received care from community doctors, about whom little information is available, contracted by the insurance plan to provide care in other communities (control patients). The study was approved by the Group Health $\mathrm{Hu}-$ man Subjects Research Committee.

Persons potentially eligible to be surveyed were randomly selected Group Health enrollees at least 18 years old who had been enrolled in the health plan for at least 12 months before sample selection and were on COT. We defined chronic opioid users as individuals who had, according to electronic pharmacy data, received at least 70 days' supply of opioids in the 90 days before sample selection and in one other quarter of the prior year coupled with at least 45 days' supply in the other 
Table 1. Questions Related to Trust and Management of Opiate Pain Medicines

Questions Asked Of Patients*

I trust my doctor's judgment in managing my opiate pain medicine

I feel my doctor trusts me in how I manage my opiate pain medicine

I sometimes worry that my doctor will stop prescribing my opiate pain medicine

My doctor, pharmacist or other providers made sure I was well informed about potential problems with opiate pain medicines

*Response options were totally disagree, disagree, neutral, agree, and totally agree.

two-quarters of the prior year. In addition, we excluded persons who had at least 2 visits with a diagnosis of cancer (apart from nonmelanoma skin cancer) or who had been admitted to hospice in the past 12 months.

Telephone surveys were conducted between September 2014 and January 2016 with eligible COT patients. The interviews lasted approximately 30 minutes to 40 minutes. All patients gave verbal consent before the surveys were administered. The survey was conducted more than 4 years after the opioid risk reduction initiatives had been implemented, so results should reflect differences observed after long-term implementation.

Most of the survey focused on pain outcomes (assessed via the validated 3-item pain, enjoyment, and general activity scale, ${ }^{21}$ which measures global pain intensity and interference), perceived opioid helpfulness, perceived opioid bothersomeness, prevalence of prescription opioid use disorder by using relevant portions of the validated Psychiatric Research Interview for Substance and Mental Disorders, ${ }^{22,23}$ prevalence of depression by using the validated Patient Health Questionnaire $8^{24}$, and various sociodemographic information. However, participants were asked how much they agreed or disagreed with 4 newly created questions about trust around COT management in the context of the doctor-patient relationship (Table 1). Each question had 5 response options: totally disagree, disagree, neutral, agree, and totally agree. For some of the results presented, we combined the categories agree and totally agree and, separately, the categories disagree and totally disagree.

Key components of the opioid risk reduction initiatives are provided in Table 2 , and additional

Table 2. Key Components of Opioid Risk Reduction Initiatives and Selected Measures of Adherence to Risk Reduction Initiatives

\begin{tabular}{rrr}
\hline & Intervention \\
Source & Clinics \\
Clinics
\end{tabular}

Washington State COT Guideline (enacted as law in March 2010) ${ }^{18}$

Check appropriateness of pain treatment

Screen for drug abuse and diversion

Group Health Opioid Risk Reduction Initiatives ${ }^{18,20,50}$

Decrease COT dose (intervention clinic dose decreased from $74 \mathrm{mg}$ MED to $46 \mathrm{mg}$ MED versus control clinic decrease from $89 \mathrm{mg}$ MED to $74 \mathrm{mg}$ MED)

Online CME followed by 1-hour discussion in each intervention clinic (87\% of primary $\quad \mathrm{X}$ care providers participated)

Medical staff leader advocacy

Designated physician to manage COT and expert consultation for physicians in each $\quad \mathrm{X}$ primary care clinic

Practice education tools (eg, patient education materials, care plan template, online $\quad \mathrm{X}$ calculator to estimate MED)

COT care plans documented in the EHR and financial incentive for completing the plans $\quad \mathrm{X}$ (documented care plans increased from $10 \%$ to over $80 \%$ over the course of the intervention)

Guideline-based monitoring visits and urine drug screening (urine drug screening increased $\quad \mathrm{X}$ from less than $15 \%$ in both intervention and control clinics to about $50 \%$ in the intervention clinics and less than $20 \%$ in the control clinics)

28-day-maximum opioid prescription and 5-day refill notice

$\mathrm{X} \quad \mathrm{X}$

$\mathrm{X} \quad \mathrm{X}$

\section{X}

X

X

X

X

COT, chronic opioid therapy; MED, morphine equvalent dose; CME, continuing medical education; EHR, electronic health record; $\mathrm{X}$, component was used in these clinics. 
details of the survey are provided elsewhere. ${ }^{18}$ In addition to survey data, we used Group Health enrollment files and electronic health record data to obtain information on characteristics including the following: patient age; sex; residence in eastern or western Washington; average opioid dose and excess days' supply; and history of diagnoses for mental health disorders, opioid and nonopioid drug use disorders, alcohol use disorders, and tobacco use disorders. By using data from the year before the interview, we computed the Romano version of the Charlson Comorbidity Index. ${ }^{25}$

\section{Nonresponse Adjustment}

By using electronic health care data available for all individuals eligible for the survey, we were able to compare the characteristics of those who completed the survey with nonrespondents. ${ }^{18}$ We then used logistic regression to estimate probability of survey response as a function of the following: patient characteristics that may be related to survey response, including the characteristics described in the previous paragraph; comorbidity score; hepatitis $\mathrm{C}$ or cirrhosis diagnoses; average opioid dose; excess days' supply ${ }^{26}$; the setting (intervention or control clinic); and interactions between these characteristics and the setting. From this model, we computed the inverse probability of response weights that were then used to weight results from the survey respondents to account for potential bias due to nonresponse. ${ }^{27-29}$

\section{Statistical Analysis}

We first reported patient characteristics of the survey respondents in the intervention and control clinics, showing the distributions of these characteristics without weighting for nonresponse. Next, we provided the raw counts for responses to each of the 4 trust questions. Then, by using the weights described earlier, we computed and reported percentages that reflect the estimated distribution of responses to the trust questions weighted to account for nonresponse. Lastly, we computed $P$ values from $\chi^{2}$ tests of whether the distribution of these (weighted) responses to each question differed between intervention and control COT patients. Analyses were performed using SAS software, version 9.4 (SAS Institute, Inc., Cary, NC).

\section{Results}

\section{Survey Participants}

We contacted 4704 COT patients who met the eligibility criteria, 2353 from the intervention clinics and 2351 from the control clinics. A total of 935 COT patients (39.7\% of those contacted) from the intervention clinics completed the interview compared with 653 COT patients $(27.8 \%)$ from the control clinics. Very few patients had missing data on the trust questions (the proportion ranged between $0.2 \%$ and $1.2 \%$ for each question).

Respondents from the intervention and control clinics were similar on most characteristics (Table 3). Substantially more respondents in the intervention clinics compared with the control clinics lived in western Washington. In addition, more respondents in the control clinics were prescribed an average daily dose of at least $120 \mathrm{mg}$ morphine equivalents, whereas more in the intervention clinics had been diagnosed with nonopioid drug use disorder and were prescribed an average daily dose of less than $15 \mathrm{mg}$ morphine equivalents, reflecting effects of the dose reduction initiatives in the intervention clinics. ${ }^{30}$ Most respondents reported that COT therapy was "very or extremely helpful," and their pain, enjoyment, and general activity scores indicated moderate to severe pain and functional impairment. $^{31}$

\section{Patient Perceptions Regarding Trust}

More than 3 in 4 COT patients (82.2\%) agreed with the statement that they trusted their doctor's judgment in managing their opiate pain medicine (Table 4), with $86.3 \%$ of COT patients in the control clinics agreeing or strongly agreeing with this statement versus $77.9 \%$ in the intervention clinics $\left(\chi^{2}=17.07 ; d f=4 ; P=.002\right)$. A high percentage $(88.7 \%)$ believed that their doctor trusted them to manage their opiate pain medicine, with somewhat more COT patients $(91.1 \%)$ in the control clinics agreeing or strongly agreeing with this statement than in the intervention clinics $\left(86.2 \% ; \chi^{2}=16.80 ; d f=4 ; P=.002\right)$. Patients who reported they did not feel their doctor trusted them were more likely to report they did not trust their doctor. Among the 73 patients who thought their doctors did not trust them, $54.5 \%$ said they did not trust their doctors. By contrast, among the 1405 patients who thought their doctors did trust them, only $3.4 \%$ said they did not trust their doctor. 


\begin{tabular}{|c|c|c|c|c|c|}
\hline & \multicolumn{2}{|c|}{$\begin{array}{l}\text { Intervention } \\
\text { Clinics }\end{array}$} & \multicolumn{2}{|c|}{$\begin{array}{l}\text { Control } \\
\text { Clinics }\end{array}$} & \multirow[b]{2}{*}{$P$ value* } \\
\hline & $\mathrm{n}$ & $\%$ & $\mathrm{n}$ & $\%$ & \\
\hline Total & 935 & & 653 & & \\
\hline Age, y & & & & & .001 \\
\hline 18 to 44 & 73 & 7.8 & 57 & 8.7 & \\
\hline 45 to 64 & 434 & 46.4 & 358 & 54.8 & \\
\hline $65+$ & 428 & 45.8 & 238 & 36.4 & \\
\hline Mean Age, y (SD) & \multicolumn{2}{|c|}{$63(12)$} & \multicolumn{2}{|c|}{$61(12)$} & .010 \\
\hline Female & 589 & 63.0 & 420 & 64.3 & .590 \\
\hline Non-Hispanic white & 783 & 84.7 & 559 & 87.3 & .147 \\
\hline At least some college & 691 & 74.0 & 448 & 68.8 & .025 \\
\hline Employment status & & & & & .008 \\
\hline Full time/part time & 314 & 33.6 & 223 & 34.2 & \\
\hline Disabled & 182 & 19.5 & 170 & 26.0 & \\
\hline Retired & 410 & 43.9 & 245 & 37.5 & \\
\hline Other & 28 & 3.0 & 15 & 2.3 & \\
\hline Married (or living as married) & 615 & 65.9 & 438 & 67.2 & .601 \\
\hline Lives in western Washington & 693 & 74.1 & 358 & 54.8 & $<.001$ \\
\hline Mental health disorders ( $\mathrm{dx}$ in past 36 months) & 623 & 66.6 & 423 & 64.8 & .444 \\
\hline Alcohol use disorder ( $\mathrm{dx}$ in past 36 months, not in remission) & 50 & 5.3 & 32 & 4.9 & .692 \\
\hline Nonopioid drug use disorder ( $\mathrm{dx}$ in past 36 months) & 89 & 9.5 & 34 & 5.2 & .002 \\
\hline Opioid drug use disorder ( $\mathrm{dx}$ in past 36 months) & 101 & 10.8 & 76 & 11.6 & .602 \\
\hline Tobacco use disorder ( $\mathrm{dx}$ in past 36 months) & 224 & 24.0 & 151 & 23.1 & .701 \\
\hline Charlson comorbidity score (based on past 12 months) & & & & & .030 \\
\hline 0 & 426 & 45.6 & 307 & 47.0 & \\
\hline 1 to 2 & 219 & 23.4 & 180 & 27.6 & \\
\hline $3+$ & 290 & 31.0 & 166 & 25.4 & \\
\hline Average COT dose (in prior quarter) & & & & & $<.001$ \\
\hline$<15 \mathrm{mg}$ & 232 & 24.8 & 96 & 14.7 & \\
\hline 15 to $<50 \mathrm{mg}$ & 432 & 46.2 & 296 & 45.3 & \\
\hline 50 to $<120 \mathrm{mg}$ & 199 & 21.3 & 150 & 23.0 & \\
\hline $120+\mathrm{mg}$ & 72 & 7.7 & 111 & 17.0 & \\
\hline Mean \# days of opioid use (in prior month) (SD) & \multicolumn{2}{|c|}{$29(3)$} & \multicolumn{2}{|c|}{$29(3)$} & .269 \\
\hline Mean PEG score (SD) & \multicolumn{2}{|c|}{$5.8(2.2)$} & \multicolumn{2}{|c|}{$5.9(2.1)$} & .708 \\
\hline Helpfulness of COT & & & & & .510 \\
\hline Not at all or a little helpful & 57 & 6.1 & 43 & 6.6 & \\
\hline Moderately helpful & 302 & 32.3 & 193 & 29.6 & \\
\hline Very or extremely helpful & 576 & 61.6 & 416 & 63.8 & \\
\hline Bothersomeness of COT & & & & & .283 \\
\hline Not at all or a little bothersome & 808 & 86.7 & 547 & 84.2 & \\
\hline Moderately bothersome & 99 & 10.6 & 86 & 13.2 & \\
\hline Very or extremely bothersome & 25 & 2.7 & 17 & 2.6 & \\
\hline
\end{tabular}

Some data were missing for race/ethnicity $(1.5 \%)$, education $(0.2 \%)$, employment $(0.06 \%)$, marital status $(0.2 \%)$, PEG score $(0.8 \%)$, perceived helpfulness $(0.1 \%)$, and bothersomeness $(0.4 \%)$ of COT.

Counts and percentages in this table describe the survey respondents only and are not weighted to account for nonresponse.

${ }^{*} P$ values are based on $\chi^{2}$ tests (for categorical variables) or $t$ tests (for continuous variables) for whether the distributions of the given characteristics differ between survey respondents in the intervention and control clinics.

COT, chronic opioid therapy; $\mathrm{dx}$, diagnosis; PEG, pain, enjoyment, and general activity.

$\mathrm{SD}$, standard deviation. 
Table 4. Distribution of Trust and Related Characteristics among Survey Responders, with Percentages Weighted to Account for Nonresponse

\begin{tabular}{|c|c|c|c|c|c|}
\hline & \multicolumn{2}{|c|}{$\begin{array}{l}\text { Intervention } \\
\text { Clinics }\end{array}$} & \multicolumn{2}{|c|}{$\begin{array}{l}\text { Control } \\
\text { Clinics }\end{array}$} & \multirow[b]{2}{*}{$\chi^{2} P$ value* } \\
\hline & $\mathrm{n}$ & $\%^{\dagger}$ & $\mathrm{n}$ & $\%^{\dagger}$ & \\
\hline Total sample & 935 & & 653 & & \\
\hline Trust doctor's judgment in managing medications ${ }^{\ddagger}$ & & & & & .002 \\
\hline Totally disagree & 15 & 1.9 & 6 & 0.9 & \\
\hline Disagree & 60 & 6.9 & 27 & 4.4 & \\
\hline Neutral & 122 & 13.3 & 59 & 8.4 & \\
\hline Agree & 308 & 33.2 & 218 & 33.9 & \\
\hline Totally agree & 426 & 44.7 & 341 & 52.4 & \\
\hline Believe doctor trusts patient in managing medications ${ }^{\ddagger}$ & & & & & .002 \\
\hline Totally disagree & 10 & 1.4 & 9 & 1.3 & \\
\hline Disagree & 41 & 4.4 & 13 & 1.9 & \\
\hline Neutral & 72 & 7.9 & 34 & 5.8 & \\
\hline Agree & 308 & 32.8 & 186 & 27.8 & \\
\hline Totally agree & 501 & 53.4 & 410 & 63.3 & \\
\hline Sometimes worry doctor will stop prescribing opioids ${ }^{\ddagger}$ & & & & & .007 \\
\hline Totally disagree & 223 & 23.7 & 196 & 29.8 & \\
\hline Disagree & 270 & 29.1 & 209 & 32.3 & \\
\hline Neutral & 163 & 17.9 & 97 & 16.0 & \\
\hline Agree & 175 & 19.1 & 102 & 15.1 & \\
\hline Totally agree & 92 & 10.2 & 42 & 6.7 & \\
\hline $\begin{array}{l}\text { Believe health care team made sure patient was well } \\
\text { informed about potential problems with opioids }{ }^{\ddagger}\end{array}$ & & & & & .924 \\
\hline Totally disagree & 7 & 0.8 & 8 & 1.2 & \\
\hline Disagree & 15 & 1.6 & 11 & 1.7 & \\
\hline Neutral & 41 & 4.3 & 32 & 4.3 & \\
\hline Agree & 318 & 33.7 & 209 & 32.1 & \\
\hline Totally agree & 553 & 59.6 & 391 & 60.7 & \\
\hline
\end{tabular}

${ }^{*} P$ values are based on $\chi^{2}$ tests of whether the distributions of responses across the 5 categories for each question differ between participants in the intervention and control clinics after weighting for nonresponse.

${ }^{\dagger}$ While n's represent the raw counts, the computed percentages are based on weighting to account for nonresponse.

${ }^{\ddagger}$ The proportion with missing data for each of the four questions were $0.4 \%, 0.3 \%, 1.2 \%$, and $0.2 \%$, respectively.

A total of $29.3 \%$ of patients in the intervention clinic and $21.8 \%$ in the control clinics said that they sometimes worried that their doctor would stop prescribing opioids $\left(\chi^{2}=14.07 ; d f=4, P=\right.$ .007). Patients who did not trust their doctors were somewhat more concerned that their doctors would stop prescribing opioids. Among the 108 patients who said they did not trust their doctor, $60.5 \%$ were worried that their doctors would stop prescribing opioids. Only 20.4\% of the 1293 patients who said they trusted their doctor reported these worries.

By contrast, over $90 \%$ of patients in both types of clinics reported that their health care teams had informed them about potential problems with opioids, with no significant differences between the intervention and control clinics $\left(\chi^{2}=0.91 ; d f=4\right.$; $P=.924)$.

\section{Discussion}

We found evidence of slightly less trust perceived by patients in the doctor-patient relationship related to management of opioid medications in the intervention clinics exposed to the opioid risk reduction initiatives. In these clinics, fewer patients agreed or strongly agreed with questions about trust in their doctor's management of opiate pain medications and their perception of their doctor's trust in their management of their opiate medications. Intervention clinic COT patients also expressed greater concern about opioids being withheld in the future. However, 
these differences of roughly $5 \%$ to $10 \%$ points in agreement between patients from the intervention and control clinics were observed in the context of highly favorable ratings of doctor-patient trust, with a large majority of patients $(82.2 \%)$ reporting that they had trust in their doctor's judgment in managing their opioid medications and that their doctors trusted them in managing their medications $(86.3 \%)$. Consistent with these findings, less than $30 \%$ of participants worried that their doctor would stop prescribing opioids.

The high levels of perceived trust are surprising considering that most of the literature about the doctor-patient relationship and opioids is about difficulties in communication and lack of trust. ${ }^{32-40}$ Possibly, COT patients who participate in focus groups and other studies of the doctor-patient relationship around opioid prescribing for chronic pain are those who are most dissatisfied with their care $^{32-35}$ and that doctors tend to remember and report interactions with the minority of COT patients where conflict and impaired doctor-patient trust are most prominent. ${ }^{32,36-39}$ If this were true, the minority of doctor-patient relationships with impaired trust could lead to overly broad generalizations regarding the difficulties of reducing opioid dose and implementing closer monitoring with more typical COT patients. The instances where doctor-patient trust is impaired may be stressful for doctors and patients alike.

Our research had several limitations. The survey response rate was low and was lower in the control clinics than the intervention group. This raises questions about how representative the survey is of the underlying population of COT users. We attempted to address this limitation by adjusting for a wide range of clinically relevant variables potentially related to survey nonresponse, including mental health disorders, overuse of alcohol and other drugs, comorbid conditions, and average opioid dose. This adjustment was possible because we had access to electronic health data for everyone selected for the sample. By randomly selecting eligible COT patients and using inverse probability weighting to adjust for nonresponse, we think that our findings reflect that of patients on longer-term COT in the Group Health population. The survey was conducted in a single health plan located in the State of Washington with a population that was largely white and well educated, so generalizability to other settings and geographic areas is not known. Our trust questions were not previously validated. No suitable surveys on patient trust in doctors regarding opioid prescribing exist. Although at least 10 general scales measure general aspects of patients trust in their doctors, ${ }^{41,42}$ all them are somewhat different. Nonetheless, our question on trusting the doctor's judgment in managing opioid pain medicine is quite similar in format to more general questions on several scales. $^{43-46}$

This was a cross-sectional study. We cannot know whether perceptions of doctor-patient trust among the intervention clinic patients were present before the opioid initiatives or developed as a result of these initiatives. It would have been ideal to have collected data on doctor-patient trust before the implementation of the initiatives in both the intervention and control clinics, but unfortunately this kind of longitudinal assessment was not possible. Nonetheless, the differences in opioid risk reduction initiatives had been sustained for at least 4 years ${ }^{47-50}$ at the time the survey was conducted, suggesting that they were robust. Differences in characteristics of COT patients between the 2 settings before implementation of the initiatives were modest. ${ }^{51}$ Comparisons of survey data regarding pain status ${ }^{31}$ and prevalence of prescription opioid use disorder ${ }^{18}$ did not find significant differences in key relevant clinical characteristics between the intervention and control populations after the opioid risk reduction initiatives. These observations support the inference that the dose and risk reduction initiatives may have reduced perceptions of trust in their doctor for some COT patients.

Our large study includes notable strengths as well. We believe it is the first survey of patient perceptions of trust in the doctor-patient relationship pertaining to the management of opioid medications. We had access to extensive electronic health care data on the entire population selected for the survey sample, which allowed us to adjust for possible nonresponse bias. The patients exposed and not exposed to the opioid risk reduction initiatives were similar in most respects and came from the same health plan. The survey was conducted after both initiatives had been implemented for more than 4 years, permitting assessment of long-term effects of the initiatives.

These findings are important given the key role that the doctor-patient relationship plays in treating chronic pain. ${ }^{2,6}$ They are consistent with more 
general studies of patients that report trust in their primary care doctors is high. ${ }^{41,42}$ We believe these results are both counterintuitive, given the published literature on the topic of opioid prescribing and the doctor-patient relationship ${ }^{32-40}$ and reassuring because they demonstrate generally high levels of patient perceptions of trust in their doctor and only modestly lower levels of trust related to opioid management among COT patients after implementation of opioid risk reduction initiatives. This suggests that it may be possible to implement opioid risk reduction initiatives while sustaining high levels of doctor-patient trust for most COT patients. However, our results also suggest that trust may be impaired among a relatively small percent of COT patients after implementation of these initiatives.

Future studies are needed that assess the impact of opioid risk reduction initiatives in more diverse populations, including younger patients, less educated patients, more disadvantaged patients, and more minority patients, all of whom might have a different experience with their doctors. For example, these groups could face greater stigma, more discrimination, and poor access to health care. Future studies should include more general questions on trust and patient satisfaction as part of the doctor-patient relationship, by using appropriate and validated measures. Understanding the impact of specific risk reduction initiatives on patient trust would be important. In addition, longitudinal studies of risk reduction initiatives of patients on COT therapy, although challenging to undertake, would be useful for understanding how patient's trust in their physicians may change over time. Our findings serve as a benchmark for such studies as well as a stimulus to investigate this topic in more depth.

We are pleased to thank the members of the Patient Advisory Committee guiding this research, including Catherine Cartwright, Penny Cowen, David Duhrkoop (chairperson), Mariann Farrell, Ada Giudice-Tompson, Kathryn Guthrie, Catherine Lippincott, Max Sokolnicki, and Betts Tully, for suggesting this series of questions as well as for their comments on the findings.

To see this article online, please go to: bttp://jabfm.org/content/ 31/4/578.full.

\section{References}

1. Kelley JM, Kraft-Todd G, Schapira L, Kossowsky J, Riess H. The influence of the patient-clinician relationship on healthcare outcomes: a systematic review and meta-analysis of randomized controlled trials. PLoS One 2014;9:e94207.

2. Lobo CP, Pfalzgraf AR, Giannetti V, Kanyongo G. Impact of invalidation and trust in physicians on health outcomes in fibromyalgia patients. Prim Care Companion CNS Disord. 2014;16.

3. Dorr Goold S, Lipkin M, Jr. The doctor-patient relationship: challenges, opportunities, and strategies. J Gen Intern Med 1999;14:S26-33.

4. Pearson SD, Raeke LH. Patients' trust in physicians: many theories, few measures, and little data. J Gen Intern Med 2000;15:509-13.

5. Vowles KE, Thompson M. The patient-provider relationship in chronic pain. Curr Pain Headache Rep 2012;16:133-8.

6. Hadi MA, Alldred DP, Briggs M, Marczewski K, Closs SJ. 'Treated as a number, not treated as a person': a qualitative exploration of the perceived barriers to effective pain management of patients with chronic pain. BMJ Open 2017;7:e016454.

7. Upshur CC, Bacigalupe G, Luckmann R. "They don't want anything to do with you": patient views of primary care management of chronic pain. Pain Med 2010;11:1791-8.

8. Clarke A, Martin D, Jones D, et al. "I try and smile, I try and be cheery, I try not to be pushy. I try to say 'I'm here for help' but I leave feeling . . . worried": a qualitative study of perceptions of interactions with health professionals by community-based older adults with chronic pain. PLoS One 2014;9:e105450.

9. Toye F, Seers K, Allcock N, et al. Patients' experiences of chronic non-malignant musculoskeletal pain: a qualitative systematic review. Br J Gen Pract 2013;63:e829-841.

10. Buchman DZ, Ho A, Illes J. You present like a drug addict: patient and clinician perspectives on trust and trustworthiness in chronic pain management. Pain Med 2016;17:1394-406.

11. Buchman DZ, Ho A. What's trust got to do with it? Revisiting opioid contracts. J Med Ethics 2014;40: 673-7.

12. Toye F, Seers K, Tierney S, Barker KL. A qualitative evidence synthesis to explore healthcare professionals' experience of prescribing opioids to adults with chronic non-malignant pain. BMC Fam Pract 2017; 18:94.

13. Group WSAMD. Interagency guideline on opioid dosing for chronic non-cancer pain: an educational aid to improve care and safety with opioid therapy. 2010 update. 2014. Published in 2014. Accessed on October 17, 2017.

14. Johnson H, Paulozzi L, Porucznik C, Mack K, Herter B. Decline in drug overdose deaths after state policy changes - Florida, 2010-2012. MMWR Morb Mortal Wkly Rep. 2014;63:569-74.

15. University PCoEaB. Mandating PDMP participation by medical providers: current status and experience in selected states. 2014. 
16. Dowell D, Haegerich TM, Chou R. CDC Guideline for prescribing opioids for chronic pain-United States, 2016. JAMA 2016;315:1624-45.

17. Inslee J. Washington State is taking action on the opioid epidemic. Available from: http://www. governor.wa.gov/sites/default/files/exe_order/ OpioidEpidemic.pdf. Published 2016. Accessed October 17, 2017.

18. Von Korff M, Walker RL, Saunders K, et al. Prevalence of prescription opioid use disorder among chronic opioid therapy patients after health plan opioid dose and risk reduction initiatives. Int J Drug Policy 2017;46:90-8.

19. Saunders KW, Davis RL, Stergachis A. Group Health Cooperative, 4th ed. In: Strom B, editor. Pharmacoepidemiology. East Essex, England: John Wiley and Sons; 2005.

20. Saunders KW, Shortreed S, Thielke S, et al. Evaluation of health plan interventions to influence chronic opioid therapy prescribing. Clin J Pain 2015; 31:820-9.

21. Krebs EE, Lorenz KA, Bair MJ, et al. Development and initial validation of the PEG, a three-item scale assessing pain intensity and interference. J Gen Intern Med 2009;24:733-8.

22. Hasin D, Samet S, Nunes E, Meydan J, Matseoane K, Waxman R. Diagnosis of comorbid psychiatric disorders in substance users assessed with the Psychiatric Research Interview for Substance and Mental Disorders for DSM-IV. Am J Psychiatry 2006; 163:689-96.

23. Hasin DS, Greenstein E, Aivadyan C, et al. The Alcohol Use Disorder and Associated Disabilities Interview Schedule-5 (AUDADIS-5): procedural validity of substance use disorders modules through clinical re-appraisal in a general population sample. Drug Alcohol Depend 2015;148:40-6.

24. Kroenke K, Strine TW, Spitzer RL, Williams JB, Berry JT, Mokdad AH. The PHQ-8 as a measure of current depression in the general population. J Affect Disord 2009;114:163-173.

25. Romano PS, Roos LL, Jollis JG. Adapting a clinical comorbidity index for use with ICD-9-CM administrative data: differing perspectives. J Clin Epidemiol 1993;46:1075-1079, discussion 1081-1090.

26. Shortreed SM, Von Korff M, Thielke S, et al. Electronic health records to evaluate and account for non-response bias: a survey of patients using chronic opioid therapy. Obs Stud 2016;2:24-38.

27. Little RJ, Rubin DB. Statistical analysis with missing data. New York: Wiley; 2002.

28. Horvitz DG TD. A generalization of sampling without replacement from a finite universe. J Am Stat Assoc 1952;47:663-85.

29. Rotnitzky ARJ. Semiparametric estimation of models for means and covariances in the presence of missing data. Scand J Stat 1995;22:323-33.

30. Von Korff M, Dublin S, Walker RL, et al. The impact of opioid risk reduction initiatives on highdose opioid prescribing for patients on chronic opioid therapy. J Pain 2016;17:101-10.

31. Thakral M, Walker RL, Saunders K, et al. Comparing pain and depressive symptoms of chronic opioid therapy patients receiving dose reduction and risk mitigation initiatives with usual care. J Pain 2018;19: 111-20.

32. Esquibel AY, Borkan J. Doctors and patients in pain: Conflict and collaboration in opioid prescription in primary care. Pain 2014;155:2575-82.

33. Blake S, Ruel B, Seamark C, Seamark D. Experiences of patients requiring strong opioid drugs for chronic non-cancer pain: a patient-initiated study. Br J Gen Pract 2007;57:101-8.

34. Vallerand A, Nowak L. Chronic opioid therapy for nonmalignant pain: the patient's perspective. Part II-barriers to chronic opioid therapy. Pain Manag Nurs 2010;11:126-31.

35. Bergman AA, Matthias MS, Coffing JM, Krebs EE. Contrasting tensions between patients and PCPs in chronic pain management: a qualitative study. Pain Med 2013;14:1689-97.

36. Harle CA, Bauer SE, Hoang HQ, Cook RL, Hurley RW, Fillingim RB. Decision support for chronic pain care: how do primary care physicians decide when to prescribe opioids? a qualitative study. BMC Fam Pract 2015;16:48.

37. Berg KM, Arnsten JH, Sacajiu G, Karasz A. Providers' experiences treating chronic pain among opioiddependent drug users. J Gen Intern Med 2009;24: 482-8.

38. Nicolaidis C. Police officer, deal-maker, or health care provider? Moving to a patient-centered framework for chronic opioid management. Pain Med 2011;12:890-7.

39. Jamison RN, Sheehan KA, Scanlan E, Matthews M, Ross EL. Beliefs and attitudes about opioid prescribing and chronic pain management: survey of primary care providers. J Opioid Manag 2014;10:375-82.

40. Kennedy LC, Binswanger IA, Mueller SR, et al. "Those conversations in my experience don't go well": a qualitative study of primary care provider experiences tapering long-term opioid medications. Pain Med. In press.

41. Hall MA. Researching medical trust in the United States. J Health Organ Manag 2006;20:456-67.

42. Rolfe A, Cash-Gibson L, Car J, Sheikh A, McKinstry B. Interventions for improving patients' trust in doctors and groups of doctors. Cochrane Database Syst Rev 2014:CD004134.

43. Anderson LA, Dedrick RF. Development of the Trust in Physician scale: a measure to assess interpersonal trust in patient-physician relationships. Psychol Rep 1990;67:1091-1100.

44. Safran DG, Kosinski M, Tarlov AR, et al. The Primary Care Assessment Survey: tests of data quality 
and measurement performance. Med Care 1998;36: 728-39.

45. Kao AC, Green DC, Davis NA, Koplan JP, Cleary PD. Patients' trust in their physicians: effects of choice, continuity, and payment method. J Gen Intern Med 1998;13:681-6.

46. Kao AC, Green DC, Zaslavsky AM, Koplan JP, Cleary PD. The relationship between method of physician payment and patient trust. JAMA 1998; 280:1708-14.

47. Thielke SM, Shortreed SM, Saunders K, Turner JA, LeResche L, Von Korff M. A prospective study of predictors of long-term opioid use among patients with chronic noncancer pain. Clin J Pain 2017;33: 198-204.
48. Von Korff M, Turner JA, Shortreed SM, et al. Timeliness of care planning upon initiation of chronic opioid therapy for chronic pain. Pain Med 2016;17:511-20.

49. Trescott CE, Beck RM, Seelig MD, Von Korff MR. Group Health's initiative to avert opioid misuse and overdose among patients with chronic noncancer pain. Health Aff (Millwood) 2011;30:1420-4.

50. Turner JA, Saunders K, Shortreed SM, et al. Chronic opioid therapy risk reduction initiative: impact on urine drug testing rates and results. J Gen Intern Med 2014;29:305-11.

51. Von Korff MSK, Dublin S, Walker RL, et al. Impact of risk reduction initiatives on rates of opioid overdose. J Pain. Under review. 